\title{
A study on relationship between English proficiency and information literacy
}

\author{
Hamidreza Hoseini Dana $^{a}$, Hamidreza Karkehabadi ${ }^{b^{*}}$, Elyas Elhami ${ }^{\mathrm{c}}$ and Faeze Moeini ${ }^{\mathrm{d}}$
}

${ }^{a}$ Department of communications, Damavand branch, Islamic Azad University, Damavand, Iran

${ }^{b}$ Phd candidate, Islamic Azad University, science and research branch, department of media management, Tehran, Iran

${ }^{c}$ Master candidate, Islamic Azad University, Neyshabour branch, department of management, Neyshabour, Iran

${ }^{d}$ Phd candidate, Islamic Azad University, Qeshm International branch, department of business management, Qeshm, Iran

\section{H R O N I C L E}

Article history:

Received June 22, 2013

Received in revised format

28 August 2013

Accepted 21 September 2013

Available online

September 242013

Keywords:

Proficiency in English

Information literacy

Islamic Azad University

\section{A B S T R A C T}

\begin{abstract}
This paper presents an empirical investigation to find the relationship between English proficiency and information literacy among some selected students from Islamic Azad University in city of Semnan, Iran. The proposed study uses regression analysis as well as Pearson correlation ratio to investigate the relationship between these two variables where information literacy is the dependent variable and English proficiency is an independent variable. The survey designed a questionnaire in four different categories and they were distributed among 364 participants out of 7200 people. Cronbach alpha has been calculated as 0.7125 , which validates the overall survey. The result of our study indicates that there was a strong correlation between these two variables $(\mathrm{r}=0.88 \mathrm{Sig} .=0.01)$, which means as student get more familiar with English language they will have better general information.
\end{abstract}

(C) 2013 Growing Science Ltd. All rights reserved.

\section{Introduction}

During the past few years, there has been a trend on availability of all sorts of documentations in English language. This means people need to become familiar with this language to take advantages of advances of information technology facilities such as social web pages, search engines, etc. English is the widely used language among foreign language speakers and throughout the world, when people with various languages come together they commonly use English to communicate. English is also the language of the Film Industry and English means we no longer have to rely on subtitles. These days, when people intend to install a software packages on their computers, they need to become familiar with Basic English language information. English language is also useful when people wish to get medical treatment in western countries.

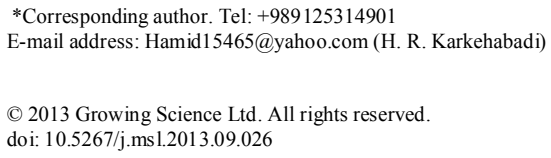


Wilson et al. (2005), for instance, determined the effect of limited English proficiency on medical comprehension in the presence and absence of language-concordant physicians. They concluded that Limited English proficiency was a major barrier to medical comprehension and increased the risk of adverse medication reactions. Leyva et al. (2005) investigated health literacy among Spanishspeaking Latino parents with limited English proficiency. They suggested that pediatricians should not assume that Spanish-speaking Latino parents who are fluently speaking English would understand a prescription label written in English, or that Latino parents who speak Spanish would understand drug information written in Spanish. Sudore et al. (2009) examined whether the impact of health literacy (HL) on patient-physician communication varies with patient-physician language concordance and communication type. They concluded that limited health literacy could impede patient-physician communication, but its impacts vary with language concordance and communication kind. For language discordant dyads, language barriers may supersede limited HL in impeding interactive communication.

Librarians who instruct students with limited English proficiency normally explain various barriers limiting effective learning. Conteh-Morgan (2002) explained how applying second language acquisition theories and teaching practices derived from them could significantly influence outcomes of information literacy instruction. Smith et al. (2013) investigated how high school students' information literacy (IL) skills help them for academic work in the digital age. The project included two sections including an audit of university IL practices and the administration of the James Madison University (JMU) Information Literacy Test (ILT) to 103 twelfth grade students in Alberta, Canada. They reported a gap between expectations of high school students and their skills. They also reported that students lack the IL proficiency required to succeed in the post-secondary educational environment.

Halle et al. (2012) investigated the development of English language learners (ELLs) from kindergarten through eighth grade within a nationally representative sample of first-time kindergartners $(\mathrm{N}=19,890)$. Growth curve analyses demonstrated that, compared to native English speakers, ELLs were ranked by teachers more favorably on approaches to learning, self-control, and externalizing behaviors in kindergarten and generally continued to rapidly grow in a positive direction on these social outcomes compared with their native English-speaking peers, holding other factors constant. Stroud and Wee (2005) investigated English language literacy practices among teenagers, focusing initially on three young Singaporean students who were struggling to do well in English. By employing a conceptual framework that construct on a recent treatment of style as identity construction and drawing on interview data that recount the students' practices of English literacy, they explained how adolescent literacy seen as style was deeply affected by, among other factors, the anticipated reactions of peers, and how these practices influence on language education. They also compared the experiences of three students with those of a fourth, one who was much more confident and comfortable with his level of English language proficiency. Ellis et al. (2013) emphasized the need to improve communication skills of pre-service teachers to be effective in their professional environment and to serve as good role models in schools.

\section{The proposed study}

In this study, we perform an empirical investigation to find the relationship between English proficiency and information literacy among some selected students from Islamic Azad University in city of Semnan, Iran. The main hypothesis of this survey is as follows,

Main hypothesis: There is a relationship between English proficiency and information literacy among some selected students from Islamic Azad University in city of Semnan, Iran. 
The proposed study uses regression analysis as well as Pearson correlation ratio to investigate the relationship between these two variables where information literacy is the dependent variable and English proficiency is an independent variable. The survey designed a questionnaire in four different categories. The sample size is calculated as follows,

$$
n=\frac{N \times z_{\alpha / 2}^{2} \times p \times q}{\varepsilon^{2} \times(N-1)+z_{\alpha / 2}^{2} \times p \times q},
$$

where $N$ is the population size, $p=1-q$ represents the yes/no categories, $z_{\alpha / 2}$ is CDF of normal distribution and finally $\varepsilon$ is the error term. Since we have $p=0.5, z_{\alpha / 2}=1.96$ and $N=7200$, the number of sample size is calculated as $n=364$. The study designed a questionnaire and distributed among 364 participants out of 7200 students who were enrolled in different levels at this school. Cronbach alpha is calculated as 0.7125 , which validates the overall survey. Fig. 1 demonstrates some of the personal characteristics of the participants.

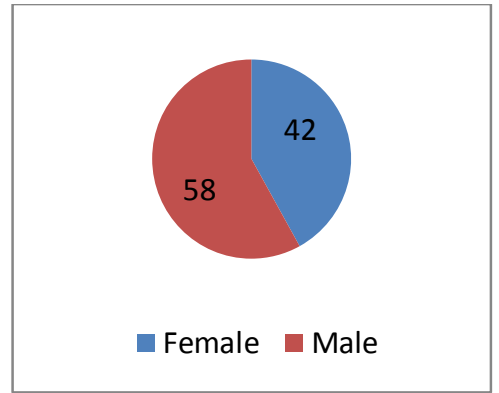

Gender

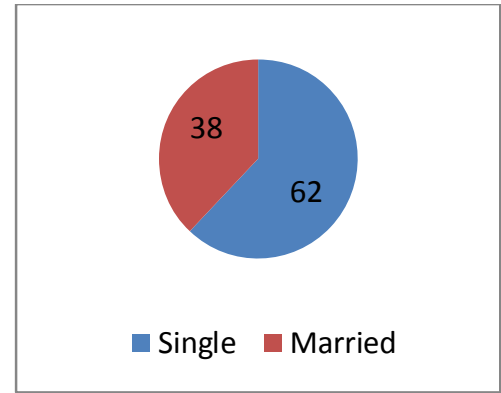

Gender

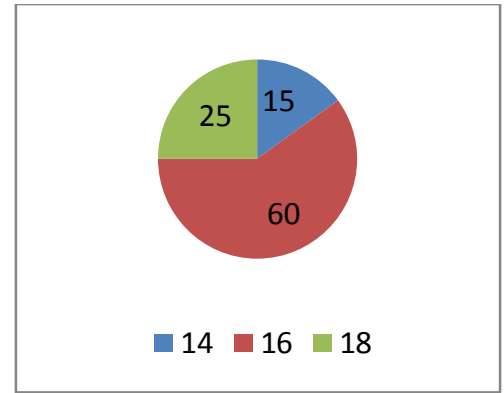

Years of educations

Fig. 1. Personal characteristics of the participants

According to Fig. 1, most participants are male, single and they were enrolled in bachelor programs. The proposed study uses Pearson correlation ratio as well as regression analysis as follows,

Information literacy $=\beta_{0}+\beta_{1}$ English proficiency $+\varepsilon_{\mathrm{i}}$.

Next, we present details of our survey on testing the results of our regression analysis.

\section{The results}

In this section, we present details of our findings on testing the relationship between information literacy and English proficiency. We first look at Pearson correlation ratio between these two variables where we have found strong and positive correlation between these variables $(\mathrm{r}=0.88 \mathrm{Sig}$. $=$ 0.01). Next, we have used SPSS software package to examine the relationship between two variables and the results are summarized as follows,

Information literacy $=0.562+0.723$ English proficiency $+\varepsilon_{\mathrm{i}}$

F-value $=154.653$ Sig. $=0.000 \mathrm{R}^{2}=0.774$ Durbin-Watson $=2.002$

As we can observe from the results of regression analysis, F-value is equal to 154.653, which is significance with $\alpha=0.01$. In addition, Durbin-Watson is equal to 2.002, which is within an acceptable value and we can make sure that there was no auto-correlation among residuals. R-Square is equal to $77 \%$, which means the regression analysis describes approximately $77 \%$ of the changes on dependent 
variable. Therefore, we can confirm the main hypothesis of this survey and state that an increase of English proficiency will help students increase their information literacy, significantly.

\section{Conclusion}

Learning English language has recently become a key success to achieve educational proficiencies, finding appropriate jobs, performing high-level research, etc. In this paper, we have performed a survey among university students who were enrolled in different areas of sciences to find out whether English proficiency could help information literacy or not. The survey has concluded that the relationship between these two components existed and it was positive. Therefore, it is recommended to university officials in Iran to provide different intensive English language programs to help students improve their language skills.

\section{References}

Conteh-Morgan, M. (2002). Connecting the dots: Limited English proficiency, second language learning theories, and information literacy instruction. The Journal of Academic Librarianship, 28(4), 191-196.

Ellis, M., Chong, S., \& Choy, Z. (2013). IELTS as an indicator of written proficiency levels: A study of student teachers at the National Institute of Education, Singapore. International Journal of Educational Research, 60, 11-18.

Halle, T., Hair, E., Wandner, L., McNamara, M., \& Chien, N. (2012). Predictors and outcomes of early versus later English language proficiency among English language learners. Early childhood research quarterly, 27(1), 1-20.

Leyva, M., Sharif, I., \& Ozuah, P.O. (2005). Health literacy among Spanish-speaking Latino parents with limited English proficiency. Ambulatory Pediatrics, 5(1), 56-59.

Smith, J. K., Given, L. M., Julien, H., Ouellette, D., \& DeLong, K. (2013). Information literacy proficiency: Assessing the gap in high school students' readiness for undergraduate academic work. Library \& Information Science Research, 35(2), 88-96.

Stroud, C., \& Wee, L. (2005). Style, identity and English language literacy. Linguistics and Education, 16(3), 319-337

Sudore, R. L., Landefeld, C. S., Pérez-Stable, E. J., Bibbins-Domingo, K., Williams, B. A., \& Schillinger, D. (2009). Unraveling the relationship between literacy, language proficiency, and patient-physician communication. Patient Education and Counseling, 75(3), 398-402.

Wilson, E., Chen, A. H., Grumbach, K., Wang, F., \& Fernandez, A. (2005). Effects of limited English proficiency and physician language on health care comprehension. Journal of General Internal Medicine, 20(9), 800-806. 